\title{
Development of Gene-Specific Real-Time PCR Screening Method for Detection of cp4-epsps Gene in GM Crops
}

\author{
Solmaz Khosravi ${ }^{1}$, Masoud Tohidfar ${ }^{1 *}$, Parisa Koobaz ${ }^{1}$ \\ Agricultural Biotechnology Research Institute of Iran, AREEO, Karaj, Iran. \\ *Corresponding author: gtohidfar@yahoo.com
}

\begin{abstract}
Among the genetically modified (GM) crops that are being approved for commercialization, herbicide resistant crops, especially those harboring cp4-epsps, have a considerable contribution. Gene-specific methods can be used to screen the presence of GMOs. To establish an effective qualitative and quantitative screening method, a set of primers were designed considering the $c p 4$ epsps sequence. The specificity, the limit of detection, the efficiency, and the ability to quantify the GMO content were tested in GM cotton, soybean, and canola events. The results demonstrated that the primers can specifically detect cp4-epsps GM crops. The limit of detection was found to be $0.4 \mathrm{ng} / \mu \mathrm{l}$ DNA per PCR reaction with the ability to detect 1-16 copies of the haploid genome of each GM event. The efficiency of this screening method (which was 94-110\% with an R2 higher than 0.96) indicated that these new primers can be applied to the screening of GM samples that contain the cp4-epsps gene. Also, the gene-specific real-time PCR screening method could be successfully developed for qualification of different types of GM cotton, soybean and canola events with the construction of a serial dilution ranging from $10 \%$ to $1 \%$.
\end{abstract}

Key words: cp4-epsps gene, GM crops, limit of detection, real-time PCR

\section{Introduction}

To meet the food demands of the world's ever-growing population, modern biotechnology has been exploited in agriculture to provide specific crops that can help build the foundation for sustainable food production (1). The crops, known as genetically modified organisms (GMOs), were cultured for the first time in 1996 in a cultivation area of 1.7 million hectares. Now, the cultivation area has reached 175.2 million hectares with 27 countries involved in the production (2). In 2013, $57 \%$ of this cultivation area belonged to herbicide-tolerant (HT) crops among which glyphosate and glufosinate tolerant varieties were the most common ones. The major HT resistant crops are cotton, canola, soybean, maize, wheat, sugar beet, potato, rice, flax, and alfalfa (2). There are several genes such as gox, als, bar, pat, and cp4-epsps (3) that are used to produce HT resistant crops. Among these genes, cp4-epsps is the most common gene being used (4).

With the production of GM crops and the increasing acceptance of such crops, authorities have made regulations to make it easier to monitor the production and use of these crops on the commercial scale. One such regulation is the labeling of GMOs (5).The threshold for unintentional presence of GMOs varies depending on each country's regulations. For example, it is $0.9 \%, 3 \%$, and $5 \%$ in the EU, Korea and, Japan, respectively (6). Australia, New Zeeland, and Brazil have reported $1 \%$ threshold for GM food labeling (6). However, for unauthorized GMOs the threshold is zero (7).

For this reason, multifarious methods, based on either protein or nucleic acid, have been developed for proper detection of GMOs. The nucleic-acid-based methods include screening, gene, construct, 
and event-specific methods (8). The screening method is usually less reliable due to yielding false positive results (9). Since some constructs are used to produce different GMOs, the construct recognition method cannot be specific and accurate enough (10). The event-specific screening method uses the unique sequences at the junction of 5' or $3^{\prime}$ flanking region of genomic DNA and inserted gene. Therefore, the above-mentioned method is very specific and has become the most important method for the identification of GM crops $(11,12)$. However, the information regarding the junction areas in different GM crops is not always available. Finally, real-time-based systems are widely being used to verify the quantification of GMOs because of their sensitivity, specificity, and also reproducibility of results (13). A real-time screening technique was developed to detect crylA.105 and cry $2 A b 2$ genes in genetically modified organisms (14). The quantitative PCR screening methods were used for the detection of Roundup Ready, LibertyLink and CryIAb traits in GM products (15). Recently, an event-specific detection system for stacked trait maize was introduced (16). The detection of soy and maize samples containing crylAb and cp4-epsps genes was performed through multiplex PCR (17). Also, PCR techniques were employed to detect $35 \mathrm{~S}$, Nos and cp4-epsps genes in GM soybean and maize (18). A multi-target Taq Man real-time PCR was developed for simultaneous detection of different GM crops including cotton, eggplant, maize, potato, rice, and soybean (19). More recently, a detection method based on loop-mediated isothermal amplification was used to monitor insect and herbicide resistant crops some of which harbored the cp4-epsps gene (20). The application of this method provided the on-site detection of GM status of samples. However, it is dependent on using three sets of specific primers to detect each gene of interest.

In the present study, we report specific primers designed for the detection of cp4-epsps gene in GM crops including soybean, canola, and cotton based on real-time assays. The primers were assayed for their specificity, limit of detection, efficiency, and the ability to quantify the GMO content.

\section{Materials and Methods}

Sample Material

Certified materials (CRMs) as reference materials harboring cp4-epsps gene including 0906-D event MON88913 cotton seed powder, 0906-B event MON89788 soybean powder, and 1011-A event MON88302 Canola were provided by AOCS (American Oil Chemists' Society, IL, USA). Non-GM materials for each crop were also provided by Seed and Plant Improvement institute, Iran. Also, CRMs lacking the cp4-epsps gene, including 0711-A event Ms1 canola and 0306-E2 event LL25 cotton, were prepared to control the specificity of designed primers.

\section{DNA Extraction}

The isolation of DNA from seed powders was carried out according Dellaporta protocol (1983) with some modifications (21). Then, all the samples were quantified using a NANO Drop 1000 spectrophotometer (Thermo Scientific, USA).

Primer Designs

Primers were designed based on the sequence of synthetic construct CP4 EPSPS glyphosate tolerance protein gene available in the National Center for Biotechnology Information (NCBI) with the accession number of JF445290. Using a blastn tool, all the sequences that showed high query coverage with cp4-epsps (JF445290) were analyzed. The selected sequences from blastn results were multiple aligned using MEGA4 (22). Using Vector NTI Software (Advanced 10, Invitrogene), a set of primers were designed from the conserved regions of the cp4-epsps gene (Table 1). Moreover, the primers for endogenous genes for each crop according to the public 
database of GMO detection method database (GMDD) were used to verify the quality of the applied DNA in PCR reactions (Table1).

\section{Polymerase chain reactions}

To confirm the presence of the cp4-epsps gene, PCR reactions with the total volume of $20 \mu 1$ containing $2 \mu \mathrm{l}$ from each of $10 \mathrm{mM}$ dNTPs, $50 \mathrm{mM} \mathrm{MgCl} 2,10 \mathrm{X}$ Taq buffer, $10 \mathrm{pM}$ of forward and reverse primers, $0.3 \mu \mathrm{l} \mathrm{Taq}$ DNA polymerase $(5 u / \mu \mathrm{l})$, and $30 \mathrm{ng}$ of DNA template were performed under the following program: $95{ }^{\circ} \mathrm{C} 5 \mathrm{~min}$., 35 cycles of $95{ }^{\circ} \mathrm{C} 30 \mathrm{~min} ., 60{ }^{\circ} \mathrm{C} 1 \mathrm{~min}$., $72{ }^{\circ} \mathrm{C} 1 \mathrm{~min}$., and $72{ }^{\circ} \mathrm{C} 3 \mathrm{~min}$. The PCR reactions to detect the endogenous genes in each crop were also performed under the same conditions. The specificity of the designed primers for the cp4-epsps gene was tested by conducting eight PCR runs for CRMs when both containing and lacking the cp4-epsps gene.

Real-time PCR

All real-time PCR reactions for the designed primers to detect cp4-epsps gene were carried out in 96-well micro-titer plate with the total volume of $25 \mu$ l containing $12.5 \mu 12 \mathrm{X}$ green star qPCR master mix (Bioneer Trade Co., China), $10 \mathrm{pM}$ of forward and reverse primers, $0.5 \mu 1$ Rox dye, DNA template, and DEPC water. Samples were amplified on MyiQ single color real-time detection system (Bio-Rad, USA) with the following program: $95{ }^{\circ} \mathrm{C} 5 \mathrm{~min}$., 35 cycles of $95{ }^{\circ} \mathrm{C}$ $30 \mathrm{Sec}, 60{ }^{\circ} \mathrm{C} 30 \mathrm{Sec} ., 72{ }^{\circ} \mathrm{C} 30 \mathrm{Sec}$, and $72{ }^{\circ} \mathrm{C} 3 \mathrm{~min}$.

The efficiency of cp4-epsps primers was evaluated using real-time PCR analysis by the serial dilution of CRMs MON88913, MON89788, and MON88302. The efficiency test was performed separately for each CRM. The final concentrations used in the analysis were 50,10, 5, 2, 0.4 and $0.08 n g / \mu 1$ DNA per PCR reaction. The ability of primers to detect the copy number in each CRM was evaluated through dividing the amount of the sample DNA (pg) by the published average 1C value for each GM crop (23). To do this, samples containing only GM $1 \%$ with the concentrations of 2 and $0.4 n g / \mu l$ DNA were applied in real-time assays. These two concentrations were selected based on the lowest concentrations which were detected in the efficiency experiments.

To set a real-time PCR-based quantification system for HT resistant samples harboring cp4-epsps gene derived from mixed samples, real-time PCR reactions were carried out on different series of CRMs to build a calibration curve based on the logarithm of each CRM content (10, 5, 2, 1 and 0 $\%)$ being plotted against $\Delta \mathrm{Ct}$ ( $\mathrm{Ct}_{\mathrm{GMO}}-\mathrm{Ct}_{\mathrm{Reference}}$ gene $)(24)$. The reference genes including lectin, $S a d 1$, and $h m g$ were used to determine the $\Delta \mathrm{Ct}$ for soybean, cotton, and canola, respectively. The different CRM contents were prepared by mixing the GM and non-GM samples. The equation obtained from this curve was used to determine the unknown percentage of HT resistant samples.

\section{Results}

Primer Design

Primers were designed based on the sequence of synthetic construct cp4-epsps glyphosate tolerance protein gene. By the use of Blastn and MEGA alignment, conserved regions of cp4-epsps gene in the available data were selected (Fig.1). Then, the primers were designed to produce 157 bp amplicons. Finally, the primers were aligned with the partial sequences of GM canola, soybean, and cotton provided by the public database GMDD and also the cp4-epsps sequences in the nucleotide sequence collection of NCBI. The query coverage resulting from this alignment was above $90 \%$.

Specificity

The endogenous genes including lectin, sadl, and hmg were successfully amplified under the specified condition and could produce amplicon sizes of 210, 107, and $219 \mathrm{bp}$, respectively (Fig 2). Non-GM cotton, canola, soybean along with MON89788 soybean and Ms1 canola were tested 
for the cp4-epsps gene. The results showed that positive controls MON89788 soybean, MON88913 cotton, and MON88302 canola produced the amplicon size of $157 \mathrm{bp}$, whereas other tested materials did not show any amplicon (Fig. 3).

Limit of detection and Efficiency

To trace the limit of detection, the different concentrations of 50, 10, 5, 2, 0.4 and $0.08 \mathrm{ng} / \mu \mathrm{lin}$ each real-time PCR reaction were used for each reference material. The lowest concentration that was detected in each sample was 0.4 ( $n g / \mu \mathrm{l})$ (Table 2). The Ct values for MON88302, MON88913, and MON89788 were 32.26, 30.81, and 32.27, respectively.

The efficiency of primers was evaluated for all three CRMs. According to the results, a linear trend was observed for all experiments when $\mathrm{Ct}$ values were plotted against the logarithm value of the DNA amount. However, $50 \mathrm{ng} / \mu \mathrm{l}$ DNA samples showed out of range results (Fig.4a, b and c). Then, they were discarded from standard curves calculations. The efficiency values for different CRMs varied from 94 to $101 \%$, and R2 was higher than 0.96 .

$\mathrm{Ct}$ mean values from real-time PCR assays in which the $1 \% \mathrm{GM}$ materials in concentrations of 2 and $0.4 \mathrm{ng} / \mu \mathrm{l}$ were used are presented for MON88302, MON88913, and MON89788 in Table 3. The copy number of cp4-epsps gene in each GM crop was calculated by dividing the DNA amount (pg) by the published average $1 \mathrm{C}$ value of $2.33 \mathrm{pg}, 1.15 \mathrm{pg}$, and $1.25 \mathrm{pg}$ for cotton, canola and soybean, respectively (25). The copy number calculated by using the sample DNA of 2 and 0.4 $n g / \mu \mathrm{l}$ from $1 \%$ GMO was 8 to 1 copies of the haploid genome of GM cotton MON88913. For canola, it was 4 to 16 copies of the haploid genome of GM canola MON88302, and it was 3 to 16 copies of the haploid genome of GM soybean MON89788.

\section{GMO quantification}

Following the optimization of PCR reactions to detect the cp4-epsps gene in different GM crops, real-time PCR reactions were completed to quantify the GM content in various samples. Reliability of experiments was confirmed by repeating the reactions for three times. The average $\mathrm{Ct}$ values of cp4-epsps gene are presented in Table 4. The $\mathrm{Ct}$ values correlated with the amount of GM content used in each assay. By increasing the GM content from $1 \%$ to $10 \%$, the $\mathrm{Ct}$ values followed a decreasing pattern. This confirms the presence of higher GM content in each mixed sample. Moreover, the samples lacking any GM $(0 \%)$ did not produce $\mathrm{Ct}$ values.

Once the logarithm of each concentration was plotted against $\Delta \mathrm{Ct}$, an equation was established upon which the GM content would become estimable (Fig 5a, b and c). The equations resulting from these calibration curves showed an R2 of 0.96-0.99.

\section{Discussion}

The specificity of primers that are used in GM detection programs is of great importance. Based on our bioinformatics analysis, conserved regions of cp4-epsps sequences in cotton, soybean, and canola and other DNA relevant data were retrieved. The designed primer pair based on conserved regions could discriminate between non-GM crops and GM crops harboring cp4-epsps with no cross-reactivity, though GM crops containing bar were not detected. Furthermore, a set of primers that could specifically identify the GM maize events harboring crylA.105 and cry2ab2 was developed (14). PCR primer sets that could amplify cry2Ab (326 bp), P35s (180 bp), T-Nos (195 $\mathrm{bp})$, and Npt-II (215 bp) in different crops were also developed (26).

The lowest amount that can be reliably detected in a sample is referred to as limit of detection (LOD). The LOD between 0.05 and $0.01(n g / \mu 1)$ DNA was detected for crylA.105 and cry $2 a b 2$ when a serial dilution of $100 \%$ CRM MON 89034 was targeted in real-time assays, which corresponds to 18 to 4 copies (14). Recently, different DNA-based detection technologies have been developed to evaluate the copy number of cp4-epsps gene in different crops $(20,19,15)$. In 
a multi-target system which was developed for the simultaneous detection of 47 targets, the system was capable of detecting 42, 6, and 88 copies of the cp4-epsps gene in cotton MON 88913, cotton MON 71800, and soybean GTS 40-3-2, respectively where the sensitivity of detection was lower than the method used in the present research (19). In another study, the lowest copy number which was detectable based on loop-mediated isothermal amplification method was 4 copies of cp4-epsps (20). In addition, the LOD of 2 copy numbers for cp4-epsps in soybean GTS 40-3-2 was reported. The established method for detection was based on coSYPS (15). The detected LOD in our experiments was $0.4 \mathrm{ng} / \mu \mathrm{l}$ DNA per PCR reaction when the $100 \%$ of the DNA input was GM. The LOD of $0.4 \mathrm{ng} / \mu 1$ DNA was also confirmed when the applied DNA contained just $1 \%$ GM content, which corresponds to 1,3, and 4 copies of the haploid genome of GM cotton, canola, and soybean, respectively. Therefore, the findings of our research are in accordance with those of Barbue and Singh. The defined threshold for the labeling of GM products in EU is $0.9 \%$ (27) which is the strictest among other countries.

The designed $c p 4$-epsps primers produced a linear quantitative curve in this research. However, the $50 \mathrm{ng} / \mu \mathrm{l}$ DNA per PCR reaction gave an out of range result that disturbed the efficiency of this method, so it was omitted from efficiency calculations. The PCR efficiency of all experiments with a serial dilution of $10,5,2,0.4$, and $0.08(n g / \mu l)$ DNA in real time PCR reaction was between $94 \%$ and $101 \%$, which is in accordance with the European Network of GMO Laboratories (ENGL) criteria (LOD below 20 target copies with PCR efficiency between $89.6 \%$ and $110.2 \%$ ) (27).

Not only the detection of specific inserted genes into crops but also the quantification of them is a concern today among authorities who supervise the production and distribution of GM crops. In our study, a standard curve for the mixture of non-GM and HT samples containing cp4-epsps was established. The presence of square regression coefficients (R2) which were higher than 0.96 for cp4-epsps gene showed this method is suitable for quantitative measurements. Calculation of GM content percentage based on the presented procedure was performed for MON863 which contains Cry $3 \mathrm{Bbl}$ (28). However, this method was based on screening and construct specific method, and the detectable LOD was 8 copies in haploid genome.

Also, the quantification of GM tomato Huafan No. 1 which contains anti-sense ethylene-forming enzyme (EFE) gene developed based on event specific primers (29). According to our experiments, the estimated GM content based on the establishment of standard curve might show a slight variation with the real content. This variation was also observed in other reports $(28 ; 29$; 30). Peccoud and Jacob (1996) reported that molecular fluctuations during real-time assays are associated with applied low copy number of template and varying amplification efficiencies. Therefore, the uncertainty associated with real-time quantification methods may occur due to these factors. Actually, when low levels of DNA from GM samples are targeted to quantitative detection methods, such variations in the measured results are probable and acceptable (31).

\section{Conclusion}

We developed an efficient and applicable real-time PCR method for the identification of various GM products including canola, soybean, and cotton based on designing new specific cp4-epsps primers. The primers were able to detect both types of cp4-epsps genes (type I and II) that exist in different crops.

\section{Acknowledgment}

The authors are grateful to Agriculture Biotechnology Research Institute of Iran (ABRII) for research facilities. 


\section{References}

1. Park JR, McFarlane I, Phipps RH, Ceddia G. The role of transgenic crops in sustainable development. Plant Biotech J. 2011; 9(1): 2-21.

2. James C. Global Status of Commercialized Biotech/GM Crops. The International Service for the Acquisition of Agri-biotech Applications (ISAAA). Brief No.44. ISAAA: Ithaca, NY. 2013.

3. Green JM, Owen MDK. Herbicide-Resistant Crops: Utilities and Limitations for HerbicideResistant Weed Management. J Agric Food Chem. 2011; 59(11): 5819-29.

4. Dill GM, CaJacob CA, Padgette SR. Glyphosate-resistant crops: adoption, use and future considerations. Pest Manag. Sci. 2008; 64: 326-31.

5. Adugna A, Mesfin T. Detection and quantification of genetically engineered crops. e- Journal of SAT Agri Research. 2008; 6: 1-10.

6. Gruère GP, Rao SR. A review of international labeling policies of genetically modified food to evaluate India's proposed rule. Ag Bioforum. 2007; 10:51-64.

7. Davison J. GM plants: Science, politics and EC regulations. Plant Sci. 2010; 178 (2):94-8.

8. Anklam E, Gadani F, Heinze P, Pijnenburg H, Van den Eede G. Analytical methods for detection and determination of genetically modified organisms in agricultural crops and plant-derived food products. Eur Food Res Technol. 2002; 214:3-26.

9. Wolf C, Scherzinger M, Wurz A, Pauli U, Hubner P, Luthy J. Detection of cauliflower mosaic virus by the polymerase chain reaction: testing of food components for false-positive 35Spromoter screening results. Eur Food Res Technol. 2000; 210:367-72.

10. Ronning SB, Va_tilingom M, Berdal KG, Holst-Jensen A. Event specific real-time quantitative PCR for genetically modified Bt11 maize (Zea mays). Eur Food Res Technol. 2003; 216 (4):34754.

11. Querci M, Paoletti C, van den Eede G. Collection of Biosafety Reviews. From sampling to quantification: Developments and harmonization of procedures for GMO testing in the European Union. Vol. 3. International Centre for Genetic Engineering and Biotechnology (ICGEB), Padricano, Trieste, Italy. 2007; pp. 7-41.

12. Miraglia M, Berdal KG, Brera C, Corbisier P, Holst-Jensen A, Kok EJ. Detection and traceability of genetically modified organisms in the food production chain. Food Chem Toxicol. 2004; 42:1157-80.

13. Milavec M, Dobnik D, Yang L, Zhang D, Gruden K, Žel J. GMO quantification: valuable experience and insights for the future. Anal Bioanal Chem. 2014; 406:6485-97.

14. Dinon AZ, Prins TW, VanDijk JP, Arisi ACM, Scholtens IMJ, Kok EJ. Development and validation of realtime PCR screening methods for detection of cry1A.105 and cry2Ab2 genes in genetically modified organisms. Anal Bioanal Chem. 2011; 400(5): 1433-42.

15. Barbau-Piednoir E, Lievens A, Vandermassen E, Mbongolo-Mbella EG, Leunda-Casi A, Roosens N, Sneyers M, Van den Bulcke M. Four new SYBR_Green qPCR screening methods for the detection of Roundup Ready_, LibertyLink_, and CryIAb traits in genetically modified products. Eur Food Res Technol. 2012; 234:13-23.

16. Shin K., Suh S., Lim M., Woo H., Hyoung Lee J., Kim H., Cho H. Event-Specific Detection System of Stacked Genetically Modified Maize by using the Multiplex-PCR Technique. Food Sci Biotechnol. 2013; 22(6): 1763-72.

17. Yoke-Kqueen C, Yee-Tyan C, Siew-Ping K, Son R. Development of multiplex-PCR for Genetically Modified Organism (GMO) detection targeting EPSPS and Cry1 Ab genes in soy and maize samples. Int Food Res J. 2011; 18: 515-22. 
18. Randhawa GJ, Frike PK, detection of transgenes in genetically modified soybean and maize using polymerase chain reaction. Indian j biotech. 2006; 5: 510-13.

19. Randhawa GJ, Singh M, Sood P, Bhoge RK. Multitarget Real-Time PCR-Based System: Monitoring for Unauthorized Genetically Modified Events in India. J Agric Food Chem. 2014; 62: $7118-30$.

20. Singh M, Randhawa GJ, Sood P, Bhoge RK. Loop-mediated isothermal amplification targeting insect resistant and herbicide tolerant transgenes: Monitoring for GM contamination in supply chain. Food Control. 2015; 51: 283-92.

http://dx.doi.org/10.1016/j.foodcont.2014.11.045.

21. Dellaporta SL, Wood J, Hicks JB. A plant DNA minipreparation version II. Plant Molecular Biology Reporter. 1983; 1, 19-21.

22. Tamura K, Dudley J, Nei M, Kumar S. MEGA4: Molecular Evolutionary Genetics Analysis (MEGA) software version 4.0. Mol Biol Evol. 2007; 24:1596-99.

23. Arumuganathan K, Earle ED. Nuclear DNA content of some important plant species. Plant Mol Biol Rep. 1991; 9(3):208-18.

24. Terry CF, Harris N. Event-specific detection of roundup ready soya using two different real time PCR detection chemistries. Eur Food Res Technol. 2001; 213:425-31.

25. European Union Reference Laboratory for GM Food and Feed. 2013.

26. Kamle S, Kumar A, Bhatnagar RK. Development of multiplex and construct specific PCR assay for detection of cry $2 \mathrm{AB}$ transgene in genetically modified crops and products. GM Crops. 2011; 2(1):74-81.

27. European Network of Genetically Modified Organism Laboratories. Definition of Minimum Performance Requirements for Analytical Methods of GMO Testing, 13 Oct., 2008. http://gmocrl.jrc.ec.Europa.eu/doc/Min_perf_requirments_Analitical_methods.pdf. accessed 22 June 2010.

28. Yang L, Xu S, Pan A, Yin C, Zhang K, Wang Zh, Zhou Zh, Zhang D. Event Specific Qualitative and Quantitative Polymerase Chain Reaction Detection of Genetically Modified MON863 Maize Based on the 5ф-Transgene Integration Sequence. J. Agric. Food Chem. 2005; 53: 9312-18.

29. Yang Ch, Zhang D, Yang L. Development of event-specific PCR detection methods for genetically modified tomato Huafan No. 1. J Sci Food Agric. 2013; 93(3):652-60

30. Yang L, Chen J, Huang Ch, Liu Y, Jia Sh, Pan L, Zhang D. Validation of a cotton-specific gene, Sad1, used as an endogenous reference gene in qualitative and real-time quantitative PCR detection of transgenic cottons. Genet Genomics. 2005; 24(4): 237-45. http://dx.doi.org/10.1007/s00299-005-0929-9.

31. Peccoud J, Jacob C. Theoretical uncertainty of measurements using quantitative polymerase chain reaction. Biophys. J. 1996; 71: 101-108.

32. Yang L, Pan A, Zhang K, Yin Ch, Qian B, Chen J, Huang Ch, Zhang D. Qualitative and quantitative PCR methods for event-specific detection of genetically modified cotton Mon1445 and Mon531. Transgenic Res. 2005; 14: 817-31.

33. James D, Schmidt A, Wall E, Green M, Masri S. Reliable detection and identification of genetically modified maize, soybean, and canola by multiplex PCR analysis. J Agric Food Chem. 2003; 51(20): 5829-34.

34. Yang L, Guo J, Zhang H, Liu J, Zhang D. Qualitative and Quantitative Event-Specific PCR Detection Methods for Oxy-235 Canola Based on the 3 Integration Flanking Sequence. J Agric Food Chem. 2008; 56(6): 1804-9. 
bioRxiv preprint doi: https://doi org/10.1101/155127; this version posted June 26, 2017. The copyright holder for this preprint (which was not certified by peer review) is the author/funder, who has granted bioRxiv a license to display the preprint in perpetuity. It is made available under aCC-BY-NC-ND 4.0 International license.
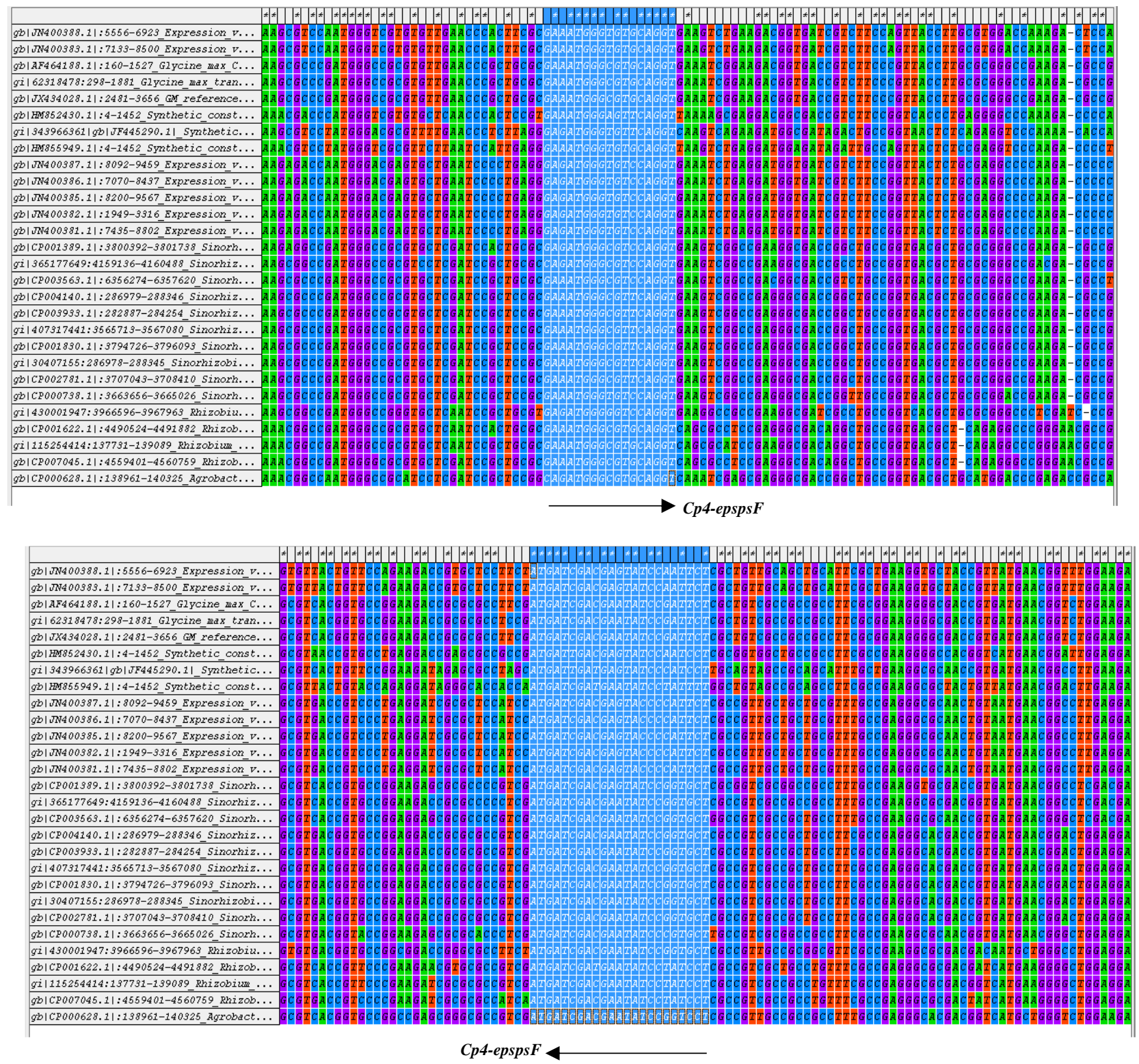

Fig. 1. Multiple aligment results on which forward primer (cp4-epspsF) and reverse primer (cp4epspsR) were desigened for recognition of cp4-epsps gene in different GM crops. 


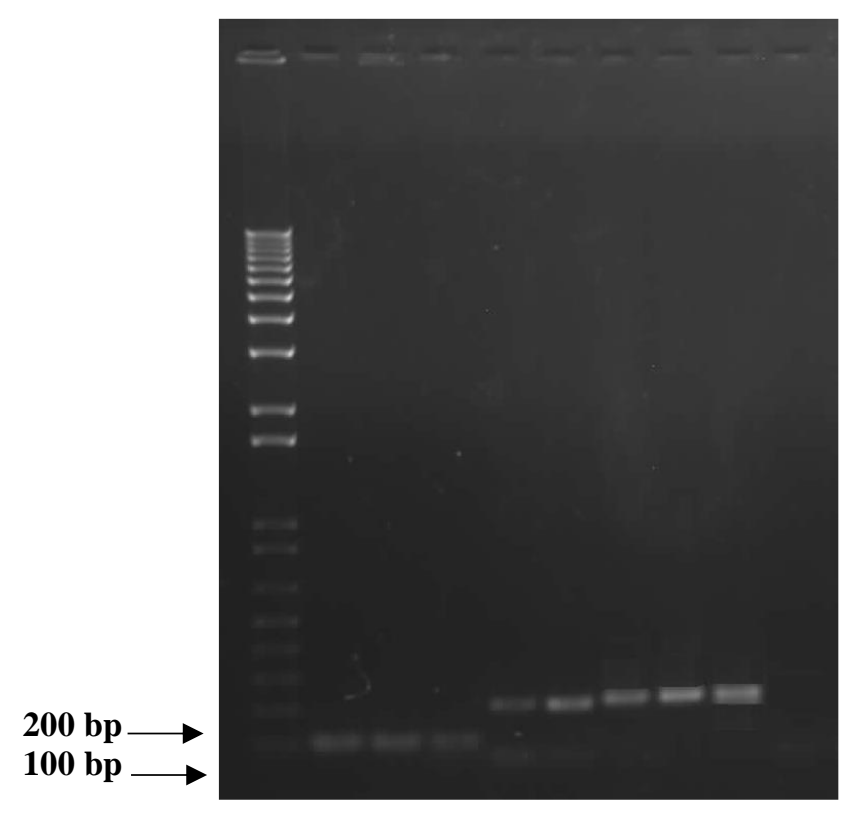

Fig. 2. One percent agaros gel electrophoresis of PCR with endogenous primers for each CRM. Lanes 1-3: Ampilication results of sadl primers in MON88913, LL25 and non-GM cotton (107 bp). Lanes 4-5: Ampilication results of primers lectin MON89788 and non-GM soybean (210 bp). Lanes 6-8: Ampilication results of $h m g$ primers in MON88302, Ms1 and non-GM canola (219 bp). Lane 9: water as negative controls. Lane M: $1 \mathrm{~Kb}$ Plus DNA ladder

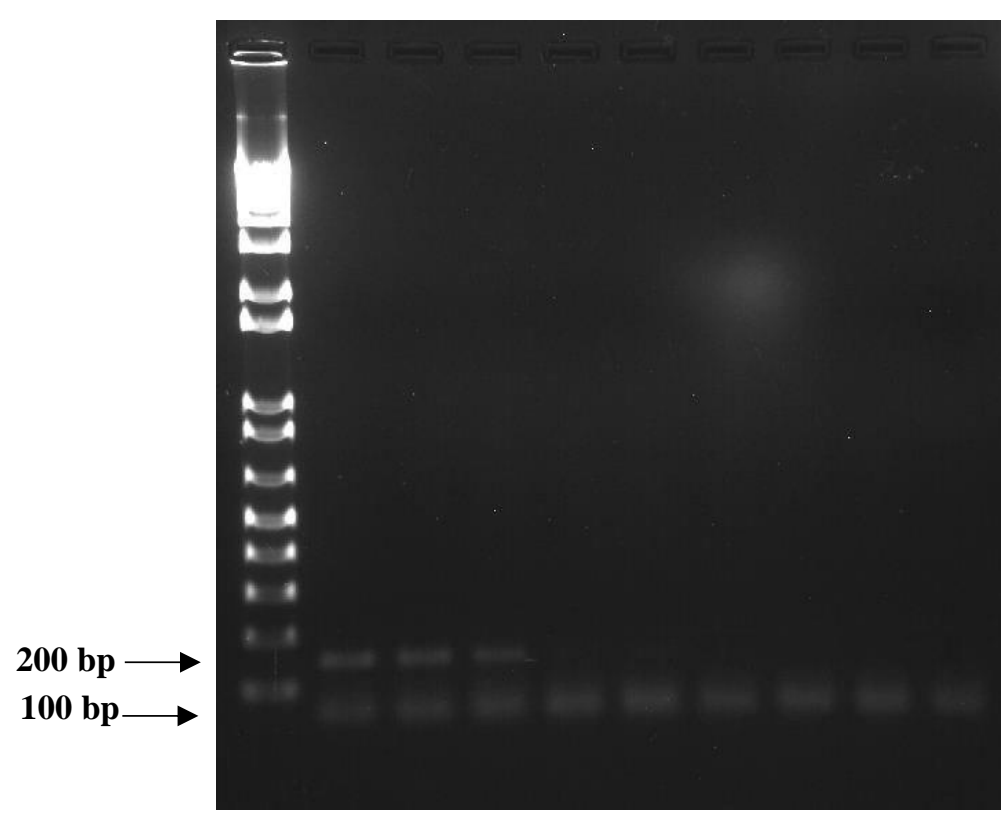

Fig. 3. 1.5 percent agaros gel electrophoresis of PCR with desigend epspps primers. Lanes 1-3: HT resistant crops MON88913 Cotton, MON89788 Soybean and MON88302 Canola (157 bp), respectively. Lanes 4-5: Msland LL25 (GM crops lacking epsps). Lanes 6-8: non-GM cotton, canola and soybean. Lane 9: Water as negative control. . Lane M: $1 \mathrm{~Kb}$ Plus DNA lad 
a Lorrelation Coefficient: 0.976 Spre: -3.24 Irtercert: $14.919 Y=-3.284 X+14.919$ PCR Efficiency: $101.6 \%$

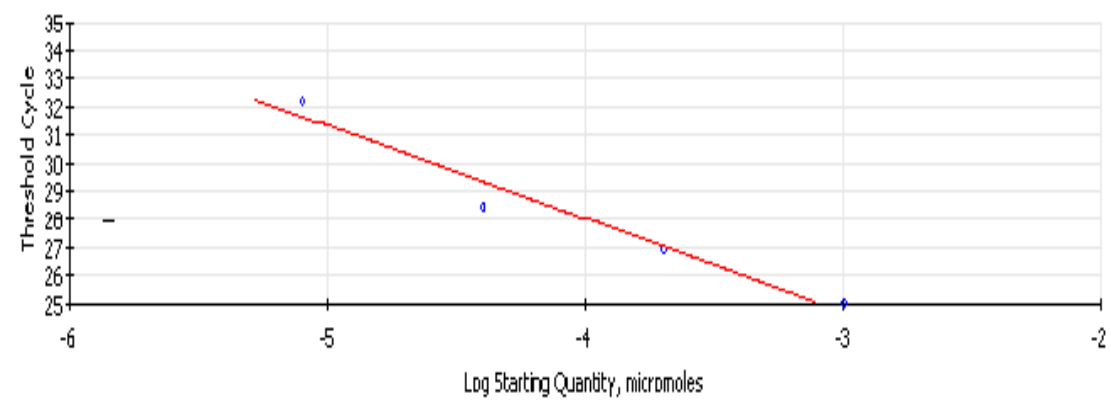

b

Corelation Coefficient: 0.992 Scpe: -3.424 Irtercert: $10.367 Y=-3.424 X+10.367$ PCR Efficiency: $95.9 \%$

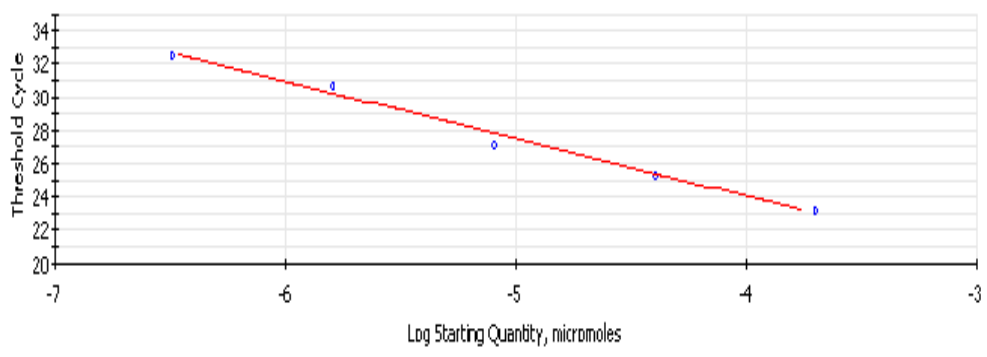

c

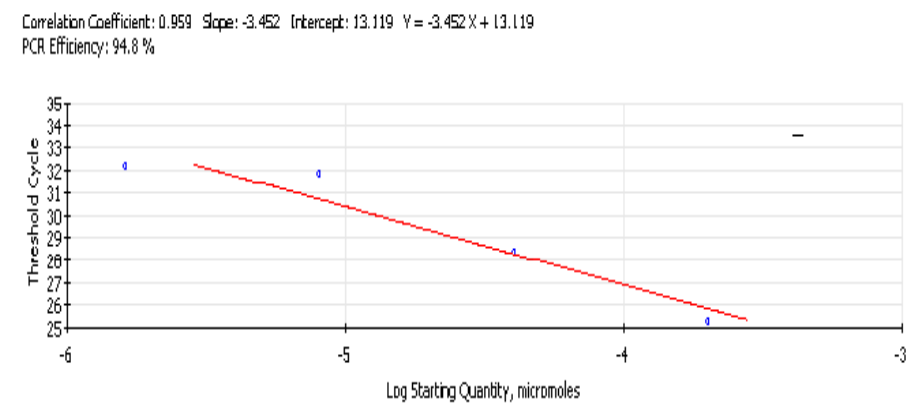

Fig 4. Linear regression of cp4-epsps gene resulted from serial dilution of 10, 5, 2, 0.4 and 0.08 ng $/ \mu 1$ DNA per real-time PCR reaction for a. MON89788 Soybean, b. MON88913 Cottonseed and c. MON88302 Canola 
a

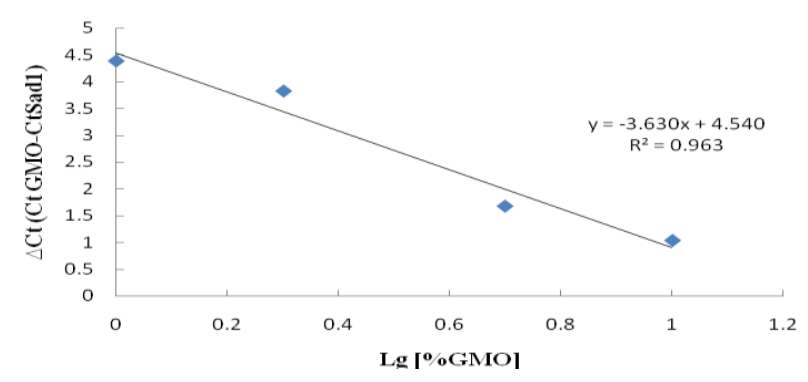

b

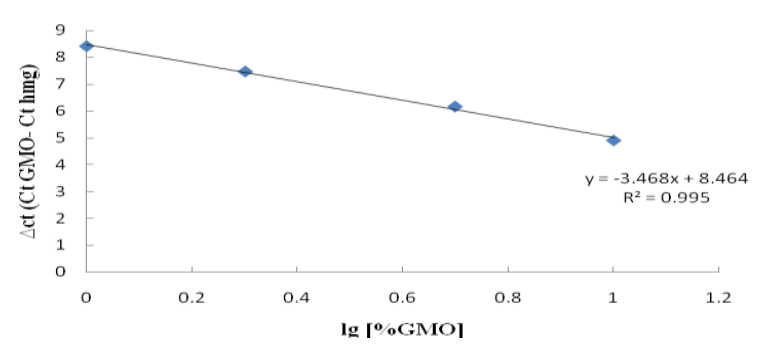

c

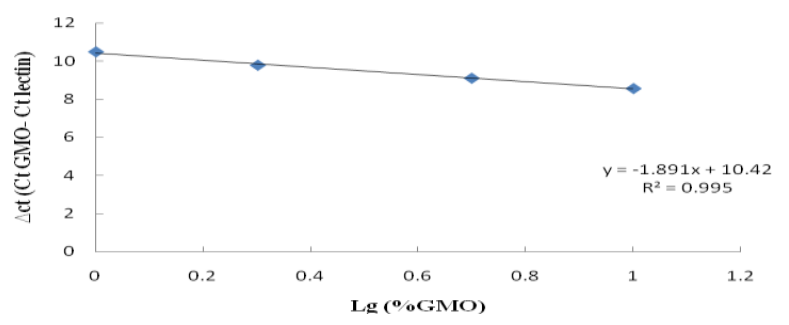

Fig. 5. Quantification equations of GM content using real-time PCR for a. MON88913 Cottonseed, b. MON88302 Canola and c. MON89788 Soybean. 
Table1. Primer sequences for detection of cp4-epsps gene and endogenous genes of cotton (sad1), soybean (lectin) and canola $(\mathrm{hmg})$.

\begin{tabular}{llcc}
\hline Gene & Primer sequence (5'-3') & Amplicon size & References \\
\hline sad1 & S1F: CCAAAGGAGGTGCCTGTTCA & 107 bp & 32 \\
& S1R: TTGAGGTGAGTCAGAATGTTGTTC & & \\
\hline lectin & lecF: GGGTGAGGATAGGGTTCTCTG & 210 bp & 33 \\
& lecR: GCGATCGAGTAGTGAGAGTCG & & \\
\hline $\boldsymbol{h m g}$ & hmg-F: GGTCGTCCTCCTAAGGCGAAAG & $219 \mathrm{bp}$ & 34 \\
& hmgR: GCAACCAACAGGCACCATC & & \\
\hline $\boldsymbol{c p}$ 4-epsps & F: 5' TGACACTGCAGGA(A/G)ATGGG 3' & 157 bp & This manuscript \\
& R: 5'- & & \\
& AGNA(T/C)NGGATACTCGTCGATCAT-3 & & \\
\hline
\end{tabular}

Table 2. Limit of detection for cp4-epsps gene in MON89788 soybean, MON88913 cottonseed and MON88302 Canola.

\begin{tabular}{cccc}
\hline $\begin{array}{c}\text { Amount of } \\
\text { DNA }(n g / \mu 1)\end{array}$ & MON89788 Soybean & $\begin{array}{c}\text { MON88913 } \\
\text { Cottonseed }\end{array}$ & MON88302 Canola \\
\cline { 2 - 4 } & & Ct mean & \\
\hline 50 & $25.11 \pm 0.08$ & $23.24 \pm 0.3$ & $25.38 \pm 0.12$ \\
\hline 10 & $27.01 \pm 0.3$ & $25.41 \pm 0.21$ & $28.45 \pm 0.18$ \\
\hline 2 & $28.47 \pm 0.44$ & $27.12 \pm 0.1$ & $31.95 \pm 0.08$ \\
\hline 0.4 & $32.27 \pm 0.43$ & $30.81 \pm 0.39$ & $32.26 \pm 0.28$ \\
\hline 0.08 & NA & NA & N/A \\
\hline
\end{tabular}

Table3. Estimated copy numbers of cp4-epsps gene in different $1 \%$ CRMs.

\begin{tabular}{cccc}
\hline Event & $\begin{array}{c}\text { Amount of } \\
\text { DNA }(\mathrm{ng} / \mu \mathrm{l})\end{array}$ & Ct mean & $\begin{array}{c}\text { Estimated Copy number per } \\
\text { PCR reaction }\end{array}$ \\
\hline MON89788 Soybean & 2 & $30.24 \pm 0.1$ & 16 \\
\hline & 0.4 & $32.16 \pm 0.15$ & 3 \\
\hline $\begin{array}{c}\text { MON88913 } \\
\text { Cottonseed }\end{array}$ & 2 & $27.21 \pm 0.13$ & 8 \\
\hline MON88302 Canola & 0.4 & $29.84 \pm 0.08$ & 1 \\
\hline & 2 & $28.63 \pm 0.09$ & 16 \\
\hline
\end{tabular}


Table4. The Ct means values of MON88913, MON88302 and MON89788 from real-time assays for $c$ 4-epsps and reference genes relating each crop.

\begin{tabular}{lccc}
\hline GM content (\%) & \multicolumn{3}{c}{ Ct mean value } \\
\hline cp4-epsps & MON88913 & MON88302 & MON89788 \\
\hline 0 & - & - & - \\
\hline 1 & $29.65 \pm 0.12$ & $33.13 \pm 0.11$ & $33.18 \pm 0.15$ \\
\hline 2 & $29.28 \pm 0.15$ & $32.19 \pm 0.15$ & $32.31 \pm 0.13$ \\
\hline 5 & $27.09 \pm 0.08$ & $30.88 \pm 0.13$ & $31.99 \pm 0.08$ \\
\hline 10 & $26.37 \pm 0.10$ & $29.63 \pm 0.07$ & $31.09 \pm 0.05$ \\
\hline Reference genes & Sad1 & $\boldsymbol{h m g}$ & lectin \\
\hline 0 & $25.41 \pm 0.45$ & $24.71 \pm 0.28$ & $22.68 \pm 0.08$ \\
\hline 1 & $25.27 \pm 0.3$ & $24.73 \pm 0.24$ & $22.70 \pm 0.13$ \\
\hline 2 & $25.46 \pm 0.27$ & $24.73 \pm 0.1$ & $22.53 \pm 0.2$ \\
\hline 5 & $25.42 \pm 0.03$ & $24.72 \pm 0.2$ & $22.89 \pm 0.33$ \\
\hline 10 & $25.34 \pm 0.39$ & $24.73 \pm 0.3$ & $22.53 \pm 0.15$ \\
\hline
\end{tabular}

